\title{
The Significance of Anthropometric Indicators in the Prediction of Abdominal Obesity in Obese Patients
}

\section{Trnkova (Lubica Trnkova)}

St. Elisabeth University of Health and Social Sciences PhD programme,

Bratislava

\section{E-mail address:}

lubicatrnkova@azet.sk

\section{Reprint address:}

Lubica Trnkova

St. Elisabeth University of Health and Social Sciences

Nam. 1. Maja

81000 Bratislava

Slovakia

Source: Clinical Social Work and Health Intervention Volume: $10 \quad$ Issue: 4

Pages:

Cited references: 18

\section{Reviewers:}

Ludmila Matulnikova

St. Elizabeth University of Health and Social Sciences, Bratislava, Slovakia

Katarina Mulama

Naivasha, Kenya

\section{Keywords:}

Abdominal Obesity. Anthropometric Indicators. Sex. Body Impedance.

\section{Publisher:}

International Society of Applied Preventive Medicine i-gap

CSWHI 2019; 10(4): 25 - 32; DOI: 10.22359/cswhi_10_4_12 @ 2019 Clinical Social Work and Health Intervention

\section{Abstract:}

Objectives: Obesity is a chronic progressive disease representing a significant health hazard and serious economic problem. As an independent risk factor it contributes to increased cardiovascular and oncologic morbidity and mortality. The IDEA study conducted in the Slovak Republic in 2017 reports that every other inhabitant in Slovakia suffers from an abdominal type of obesity. Therefore, anthropometric indica- 
tors are recommended in the process of screening for early identification of the abdominal type of obesity.

Aim: The aim of the study is to determine the evaluation significance level of chosen anthropometric indicators for early abdominal obesity prediction.

Methods: Empiric data were ascertained by standardized anthropometric methods. We evaluated waistline, WHR, VFA, weight, height and $\mathrm{BMI}$ in relation to sex. The In Body 230 device was used to measure the body impedance, and the questionnaire to ascertain somatic indicators. Our research was conducted with 201 male and 301 female respondents aged between 20 and 65 . The choice of respondents was purposive and we followed all essential ethical principles for research data collection. Respondents had provided their written consent to research data collection and were provided with instructions regarding anthropometric measurements and informed about its results. The data collection took place in Zvolen and Banska Bystrica in 2018 as a part of the project "Get rid of your excess weight". Empiric data were processed with the SPPS 22.0 statistical program. We used descriptive statistics, calculated Pearson's correlation coefficient $r$ with the corresponding determination coefficient $r^{2}$. We applied Fisher's transformation r-z to draw a comparison between correlation coefficients.

Results: Abdominal obesity was determined in $77.1 \%$ of male and $88 \%$ of female respondents using waistline measurements. We could identify $55.2 \%$ abdominally obese male and $98 \%$ abdominally obese female respondents using WHR index measurements. Visceral fat over the standard level was determined in $93.5 \%$ male and $92 \%$ female respondents. The intersection of the waistline measurement values, WHR index and visceral fat over the standard level determined $54.7 \%$ abdominally obese male and $82.7 \%$ abdominally obese female respondents. According to WHO classification, BMI between overweight and 3rdgrade obesity could be determined in our respondents.

Conclusion: For abdominal obesity identification, it is necessary to take index WHR and visceral fat values into account in relation to sex. The anthropometric factors, e.g. BMI and WHR, waistline and WHR, waistline and VFA were higher in men than in women. Anthropometric adiposity indices are assessed as effective for clinical practice in the process of overweight and obesity monitoring.

\section{Introduction}

Obesity is a serious chronic multi-factorially induced disease characterized as an illness and at the same time as a risk factor contributing to the development of other diseases. Obesity is accompanied by accumulation of an excessive amount of fat in relation to muscles, age, height and sex. It is considered the second most common risk factor for premature death.

This disease is a result of genetic predisposition, and behavioral and environmental factors interaction (Hainer et al. 2011; WHO 2003, 2009; Richens, Lavander 2010; Mat- 
ulnikova 2012, 2013). This phenomenon has an increased tendency in developed and developing countries and is slowly getting pandemic. According to $\mathrm{WHO}$, the number of obese people in 1995 was 200 million worldwide, and in 2000 it was 300 million. The number increased to 700 million obese people over 15 in 2015. More than a billion adults and $10 \%$ of children are overweight or obese. By using different classification for diverse ethnic groups, the number of people suffering from this disease goes up to 1.7 billion (WHO 2010; Kunesova et. al. 2016).

The waistline is a very important predictor of health-related conditions and mortality connected to obesity. Abdominal obesity is related to a higher risk of death. Relative risk is more significant in the young in comparison to the elderly, and in people with lower BMI in comparison to the ones with higher BMI. Epidemiologic studies conducted in European countries and in North America specialized in population's waistline evaluation ascertained the fact that waistline represents more sensitive lifestyle change indicator than BMI which, however, can be influenced by the season of the year in a significant way (Visscher, Seidell 2004; Hainer et al. 2011; Krahulec et al. 2013). The increase of $2.7 \mathrm{~cm}$ in male waistline and $4.3 \mathrm{~cm}$ in female waistline was detected in the Finnish population between the years 1987 and 2002 (15 years). The increase was not conditional on education in both sexes; however, the highest values were detected in people with primary education. BMI did not change significantly in the above mentioned period (Lahti - Koski et al. 2007). The increase of an average waistline adjusted to the respondents' age was ascertained by comparing the data of American population in the years $1988-1994$ and $2003-$ 2004, particularly, 96.0 to $100.4 \mathrm{~cm}$ in man and 89 to $94 \mathrm{~cm}$ in women. The prevalence of abdominal obesity adjusted to respondents' age increased from $29.9 \%$ to $42.4 \%$ in men, and from $47 \%$ to $61.3 \%$ in women between the years 1988 and 2004. Very similar data were gained in China where the figures showed the increase of waistline from 77.1 to $82.9 \mathrm{~cm}$ in men, and from 75.8 to $78.9 \mathrm{~cm}$ in women between the years 1993 and 2006. At the same time, the prevalence of abdominal obesity increased from $17.9 \%$ to $42.5 \%$ in men, and from $28.8 \%$ to $46.9 \%$ in women. In China; there were $42.5 \%$ of men and $46.9 \%$ of women suffering from abdominal obesity in the year 2006 (Beydoun, Wang 2009; Hainer et al. 2011). The Slovak version of the IDEA study with 4,085 patients $(1,624$ men $-39.8 \%, 2,461$ women $-60.2 \%$ ) conducted in the Slovak Republic stated high prevalence of abdominal obesity in the SR. The study shows

that every other adult inhabitant has a raised intraabdominal fat volume. The obesity was ascertained in every third woman $(34.7 \%)$ and in every fourth man (27\%). The prevalence of main risk factors for serious diseases as hypertension, hyperlipidemia and diabetes mellitus increased along with an increased waistline (Dukat et.al. 2007; Matulnikova et al. 2010, Krahulec et al. 2013).

\section{Methods}

The representative sample consisted of 502 respondents ( $40 \%$ male, $n=201,60 \%$ female, $n=301$ ) aged between 20 and 65 . The choice of respondents was purposive and we followed all the essential ethical principles for the research data collection. Respondents had provided their written consent to research data collection and were provided with instructions regarding anthropometric measurements, and informed about its results. The data collection took place in Zvolen and Banska Bystrica in May 2018 as a part of the project "Get rid of your excess weight". Empiric data were ascertained using standard anthropo-metric devices and 
recorded into the structured indicator sheet. Clinical parameters were ascertained with the bioelectrical impedance method. We were ascertaining the portion of excess weight and obesity in monitored population according to WHO classification of Body Mass Index BMI. We calculated BMI from body height and body weight. BMI in men in the monitored group of respondents was between 24.5 and 61.3. The average BMI was 33.718 (SD $=6.24$ ). BMI in women was between 22.2 and 56. And the average BMI was 32.99 (SD $=5.97$ ). According to WHO Body Mass Index classification $1 \%$ of male respondents had normal body weight $(n=2) ; 26.9 \%$ of male respondents had an excess weight $(\mathrm{n}=$ $24) ; 41.3 \%$ of male respondents had $1^{\text {st }}$-grade obesity $(\mathrm{n}=83) ; 19.4 \%$ of male respondents had $2^{\text {nd }}$-grade obesity $(n=39) ; 11.4 \%$ of male respondents had $3^{\text {rd }}$-grade obesity $(n=23)$. In the group of female respondents, according to WHO Body Mass Index classification $2 \%$ of female respondents had normal body weight $(n=6) ; 34.2 \%$ of female respondents had an excess weight $(\mathrm{n}=103) ; 35.9 \%$ of female respondents had $1^{\text {st }}$-grade obesity ( $n$ $=108) ; 15.3 \%$ of female respondents had $2^{\text {nd }}$-grade obesity $(n=46) ; 12.6 \%$ of female respondents had $3^{\text {rd }}$-grade obesity $(\mathrm{n}=38)$. Having the same BMI, women have a higher ratio of fat than men, and older individuals have a higher ratio of fat than younger individuals. The negative aspect is that the BMI values may not correlate with the adipose tissue accumulation level as body weight is taken into account when calculating BMI. The body constitution itself (particularly ratio and distribution of muscular and adipose tissues) is not reflected in BMI. This was the reason why our abdominal fat metering was based on the waistline metering using tailor's tape measure in the horizontal position in between lower margin of the last rib and the ridge of ilium bone at the end of a natural expiration. Waistline measured this way best correlates with the visceral fat amount and the risk of cardiovascular conditions. As for the clinical parameters, we measured respondents' actual body height $( \pm 0.5 \mathrm{~cm})$ using the altimeter Trystom (Czech Republic). The Bioelectric Impedance method based on the body resistance, more precisely body conductivity, measurement by means of current flow of low frequency (500mA) and high frequency (50 $\mathrm{kHz}$ ) was used to ascertain body composition parameters as body weight, body water, body fat percentage, BMI, WHR, fat and muscles segmental evaluation and the amount of visceral fat. This method takes better conductivity of fatless body mass in comparison to fat issues acting as insulator into account. In Body Biospace 230 device was used. When measuring, the correction in connection to sex, body weight and body height of a respondent was made. The acquired data were analyzed with a personal computer and the body composition analysis was made with specializ ed software. We evaluated acquired indicators in relation to sex. Persons with an implanted artificial pacemaker, electronic implants, after bariatric surgery, with endocrine obesity, active sportspeople, people with normal BMI and pregnant women were excluded. The empiric data were processed with the statistical program SPPS 22.0. We used descriptive statistics, calculated Pearson's correlation coefficient $r$ with the corresponding determination coefficient $r^{2}$. We applied Fisher's transformation $r-z$ to draw a comparison between correlation coefficients.

\section{Results}

The average male waistline was $\mathrm{M}=$ $113.72 \mathrm{~cm}(\mathrm{SD}=14.09 \mathrm{~cm})$. Minimal value was $\mathrm{Min}=87 \mathrm{~cm}$ and maximal value was Max $=164 \mathrm{~cm} .77 .1 \%$ of men $(n=155)$ were diagnosed with abdominal obesity (waistline $>102 \mathrm{~cm})$. The average female waistline was $\mathrm{M}=101.76 \mathrm{~cm}(\mathrm{SD}=134.31 \mathrm{~cm})$. Minimal value was $\mathrm{Min}=79 \mathrm{~cm}$ and maximal value was $\operatorname{Max}=149 \mathrm{~cm} .88 \%$ of wom- 
en $(n=265)$ were diagnosed with abdominal obesity (waistline $>88 \mathrm{~cm}$ ). The average WHR value in men was $\mathrm{M}=1.02$ ( $\mathrm{SD}=$ 0.11 ) in the range 0.42 and 1.75 . According to this index, abdominal obesity (WHR > 1) was identified in $55.2 \%$ men $(n=111)$. The average WHR value in women was $\mathrm{M}$ $=0.99(\mathrm{SD}=0.07)$ in the range 0.71 and 1.2. Abdominal obesity (WHR $>0.85$ ) was identified in $98 \%$ women $(n=295)$. Visceral fat in male respondents varied from $55.2 \mathrm{~cm}^{2}$ to $299.4 \mathrm{~cm}^{2}$. The average value was $\mathrm{M}=$ $148.96 \mathrm{~cm}^{2}\left(\mathrm{SD}=44.75 \mathrm{~cm}^{2}\right)$. Based on this index, abdominal obesity was identified in $93.5 \%$ of men $(n=188)$. Visceral fat in female respondents varied from $67.9 \mathrm{~cm}^{2}$ to $278.8 \mathrm{~cm}^{2}$. The average value was $\mathrm{M}=$ $150.1 \mathrm{~cm}^{2}\left(\mathrm{SD}=39.72 \mathrm{~cm}^{2}\right)$. Based on this index, the abdominal obesity was identified in $92 \%$ of men $(n=188)$. In the intersection of all the 3 indicators showed presence of abdominal obesity in $54.7 \%$ of male respondents $(n=110)$ and in $82.7 \%$ of female respondents while BMI varied from overweight to the $3^{\text {rd }}$-grade obesity in both sexes. Studying connections between 4 indicators of overweight and obesity showed statistically significant positive relation $(\mathrm{p}$ $<0.001$ ) among BMI, waistline, WHR index and visceral fat (the combination of all pairs). Acquired correlation coefficients can be found in Table 1 below.

We could determine a closer relation between BMI and WHR in men when com- paring the measurement of the correlation coefficient in men and women. BMI explains $43.3 \%$ of WHR variance in men and $13.18 \%$ of WHR variance in women $(Z=$ $4.46, \mathrm{p}=0.000)$. Also, the closer relation between waistline and WHR $(Z=3.06, p$ $=0.002$ ) was determined in men than in women. Waistline explains $37.7 \%$ of WHR variance in men and $16.73 \%$ of WHR variance in women. Finally, the closer relation between waistline and visceral fat $(Z=2.46$, $\mathrm{p}=0.014$ ) was determined in men in comparison to women. In this case, waistline explains $47.33 \%$ of the visceral fat variance in men and $30.25 \%$ of the visceral fat variance in women. The value of visceral fat in women ranged between $67.9 \mathrm{~cm}^{2}$ and $278.8 \mathrm{~cm}^{2}$. An average value was $\mathrm{M}=150.1 \mathrm{~cm}^{2}(\mathrm{SD}=$ $39.72 \mathrm{~cm}^{2}$ ). According to this index, abdominal obesity was identified in $92 \%$ of women $(n=188)$.

\section{Discussion}

Fat distribution is an important indicator of the risk determination of overweight and obesity. Waistline measurement can identify a twice as high prevalence of people suffering from abdominal obesity as obesity criteria according to BMI (Barakova, 2009 Matulnikova, Mizerska 2019). BMI does not evaluate the ratio of active body weight to body fat. This can result in an incorrect and erroneous interpretation in personal weight

Table 1: Pearson's correlation coefficient for overweight and obesity indicator pairs.

\begin{tabular}{|l|l|l|l|l|l|l|c|}
\hline & & Waistline & $\mathrm{r}^{2}$ & WHR & $\mathrm{r}^{2}$ & VFA & $\mathrm{r}^{2}$ \\
\hline \multirow{2}{*}{ BMI } & Men & $0.619^{* *}$ & 0.383 & $0.658^{* *}$ & 0.433 & $0.890^{* *}$ & 0.792 \\
\cline { 2 - 8 } & Women & $0.554^{* *}$ & 0.307 & $0.363^{* *}$ & 0.132 & $0.884^{* *}$ & 0.781 \\
\hline \multirow{2}{*}{ waistline } & Men & & & $0.614^{* *}$ & 0.377 & $0.688^{* *}$ & 0.473 \\
\cline { 2 - 8 } & Women & & & $0.409^{* *}$ & 0.167 & $0.550^{* *}$ & 0.303 \\
\hline \multirow{2}{*}{ WHR } & Men & & & & & $0.684^{* *}$ & 0.468 \\
\cline { 2 - 8 } & Women & & & & & $0.594^{* *}$ & 0.353 \\
\hline
\end{tabular}

** $\mathrm{p}<0.001 ; \mathrm{r}^{2}-$ coefficient of determination 
categorization. A person may be categorized as obese according to BMI in consequence of higher muscle mass, however, not in connection with body fat. Similarly, erroneous interpretation is possible with normal BMI index when a person's muscle mass ratio is low but the body fat ratio is high. This is characteristic for so-called hidden obesity. The overweight or obesity evaluation solely according to BMI index is not sufficient and reliable. The accurateness and reliability of BMI calculation might also be influenced by more factors necessary to take into consideration, e.g. age and sex. ures 0.7; this can be seen as one of the factors decreasing the value of anthropometric indicators in prediction. In NEMESYS study, the prevalence of abdominal obesity and metabolic syndrome was monitored in 10,300 Slovak outpatients. Abdominal obesity was ascertained in $65.9 \%$ of patients, where $72.6 \%$ were women and $56.6 \%$ men. The highest abdominal obesity prevalence was proved in the fifth and sixth decennium (Lietava et al. 2008, Krahulec et al. 2013). In clinical practice, the use of anthropometric indicators is recommended to the evaluation of fat deposition and abdominal obesity

Chart 1 Presence of abdominal obesity in men and women based on 3 indicators

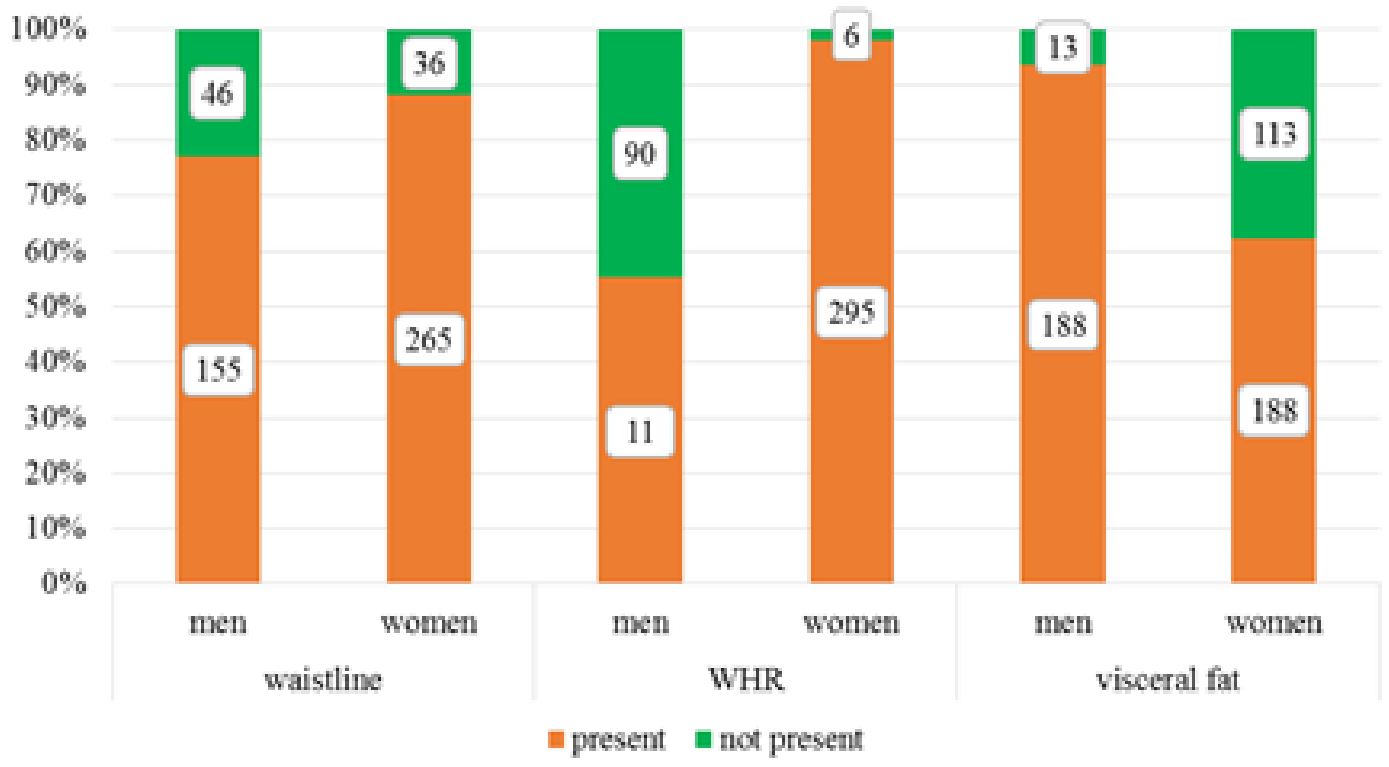

Waistline highly correlates with BMI and abdominal obesity correlates with insulin resistance and with other metabolic syndrome factors. The waistline is a simple anthropometric indicator which correlates best with intra-abdominal fat tissue volume and with the commencement of complications (Dukat et al. 2007; Kalousova, Kunesova, 2008). Kunesova (2016) states the volume of visceral or intra-abdominal fat correlates with anthropometric indicators, however, the correlation coefficient is in around fig-

risks. These simple and non-invasive methods are considered suitable and important for screening program implementation. In daily clinical practice waistline measurement represents a simple tool for screening and examination.

\section{Conclusion}

The aim of prophylactic strategies is to decrease the prevalence of overweight and obesity in the whole population by creating an anti-obesogenic environment. Interven- 
tion programs make use of cognitive-behavioral approaches and they are focused mainly on diet adjustment, active movement and health hazard identification. The identification of risk population and early overweight and obesity diagnostics in primary step are included in prophylactic programs. Diagnostic values of anthropometric factors are considered effective adiposity factors. They can act as important predictors for abdominal obesity, however, age, sex and the morbidity of the monitored population must be taken into consideration.

\section{References:}

1. BARAKOVA A (2009) Epidemiological situation in Slovakia - circulatory system diseases and their risk factors. In: Via Practica. 2009. Vol. 6, No1, p. 17-21. ISSN 1336-4790.

2. BEYDOUN MA, WANG Y (2009) Gender - ethnic disparity in BMI and waist circumference distribution shifts in US adults. Obesity /Silver Spring/ 17:169-176.

3. DUKAT A, LIETAVA J, KRAHULEC B. et al. (2007) Prevalence of abdominal obesity in Slovakia. Study by DEA Slovakia. In: Internal Medicine. 2007. Vol. 53, No 4, p. 326 - 330. ISSN 0042-773X.

4. HAINER V et al. (2011) Basics of clinical obesitology. 2nd, revised and supplemented edition. Praha: Grada Publishing 2011. p.422, ISBN 978-80-247-3252-7.

5. KALOUSKOVA P, KUNESOVA M (2008) Obesity - a still underestimated disease. In: Medicine for practice. 2008; 5(1):6-8.

6. KRAHULEC B (2013) Obesity epidemiology. In: Clinical obesitology. Facta Medica. Brno; 2013: 23-26.

7. KUNESOVA M et al. (2016) Basics of obesitology. Praha: Galen. 2016. p. 172, ISBN 978-80-7492-217-6.

8. LAHTI - KOSKI M, HARALD K, MANNISTO S, LAATIKAINEN T, JOUSILAHTI, P (2007) Fifteen - year changes in body mass index and waist circumference in Finnish adults. Eur J Cardiovasc Prev rehabil, 14:398-404.
9. LIETAVA J, KOSMALOVA V, HUSAROVA V et al. (2008) Treatment of metabolic syndrome in Slovakia. In: Via Practica. 2008. Vol. 5, p. 1 -13.

10. MATULNIKOVA L, LULJAKOVA J (2010) Management of a pregnant woman with gestational diabetes mellitus. Assisting Professions. Otto Printing Office, Prague 2010, p.49-58, ISBN 978-80- 254- 8014-4.

11. MATULNIKOVA L (2012) Management weight of pregnant women with obesity. $\mathrm{Ru}-$ zomberok, Verbum 2012. p. 108, ISBN 97880-8082-519-5.

12. MATULNIKOVA L (2013) Body Weight Monitoring as a Tool For Identification Of Risks In a Pregnant Woman. Book Editor(s) Jurenikova, P., Strakova, J., Pospisilova, A. International Conference of General Nurses and Workers Educating Paramedical Staff. Published and printed by National Centre Of Nursing and other Health Professions, 2013, Masaryk Univ, Med Fac, Dept Nursing, Brno, CZECH REPUBLIC. ISBN 978-80-7013- 558-7

13. MATULNIKOVA L, MIZERSKA K (2019) Application of Mercer Model In The Evaluation Of The Risk Factors Of Obesity For Pregnant Women. Vol. 34, No 3 (2019): Scientific Journal of Polonia University doi: $10.23856 / 3415$.

14. RICHENS Y, LAVANDER T (2010) Care for Pregnant Women who are Obese. 2010. Huntingdom Cambridgeshire, s. 254. ISBN10:1 856423885.

15. VISSCHER TL, SEIDELL JC (2004) Time trends /1993-1997/ and seasonal variation in body mass index waist circumference in the Netherlands. Int J Obes Relat Metab Disord 2004, Oct 28 /10/: 1309-1316.

16. World Health Organization (2003) Global Strategy of Diet, Physical Activity and Health /Obesity and Overweight/. [cit.201812-29]. Dostupné na: <http://www.who.int/ hpr/NPH/docs/gs_obesity.pdf $>$.

17. WHO (2009) Obesity: Preventing and managing the global epidemic: Report of a WHO consultation on Obesity, World Health Organization, Geneva 2009. 269 p. ISBN-13: 978-9241208949.

18. WHO (2010) Global Recommendations on Physical Activity for Health. p. 58, 
ISBN 9789241599979 [online] [cit. 2018-13-12]. Dostupné na: <http://webcache.googleusercontent.com/search? $\mathrm{q}=\mathrm{ca}-$ che:xgCWc2xgBWIJ:whqlibdoc.who.int/ publications/2010/9789241599979 eng. pdf + who $+2010+$ global + recommendation$\mathrm{s}+\mathrm{on}+$ physical + activity $\& \mathrm{hl}=\mathrm{sk} \& \mathrm{gl}=\mathrm{sk}>$. 